\title{
RESEARCH ARTICLE Cerebellar developmental deficits underlie neurodegenerative disorder spinocerebellar ataxia type 23
}

\author{
Cleo J.L.M. Smeets ${ }^{1}$ (D); KaiYu Ma2 (D); Simon E. Fisher ${ }^{1,3}$; Dineke S. Verbeek ${ }^{2, *}$ (DD \\ 1 Department of Language and Genetics, Max Planck Institute for Psycholinguistics, Nijmegen, the Netherlands. \\ 2 Department of Genetics, University of Groningen, University Medical Center Groningen, Groningen, the Netherlands. \\ 3 Donders Institute for Brain, Cognition and Behaviour, Radboud University, Nijmegen, the Netherlands.
}

\section{Keywords}

ataxia, climbing fibers, development, GABAergic transmission, prodynorphin.

\begin{abstract}
Abbreviations
AMPA, $\alpha$-amino-hydroxy-5-methylisoxazole-

4-propionate; BC, basket cell; CF, climbing

fiber; Dyn, Dynorphin; GAD67, glutamate

decarboxylase 67; NMDA, N-methyl-_-

aspartate; PC, Purkinje cell; PDYN,

prodynorphin; PF, parallel fiber; SCA,

spinocerebellar ataxia; vGAT, vesicular

GABA transporter; VGCC, voltage-gated

calcium channel; vGlut, vesicular glutamate transporter.
\end{abstract}

\section{Corresponding author}

Dineke S. Verbeek, Department of Genetics, University of Groningen, University Medical Center Groningen, PO Box 30001 , Groningen 9700 RB, the Netherlands (E-mail:d.s.verbeek@umcg.nı)

Received 28 May 2020

Accepted 7 October 2020

Published Online Article Accepted 00

Month 2020

doi:10.1111/bpa.12905

\begin{abstract}
Spinocerebellar ataxia type 23 (SCA23) is a late-onset neurodegenerative disorder characterized by slowly progressive gait and limb ataxia, for which there is no therapy available. It is caused by pathogenic variants in PDYN, which encodes prodynorphin (PDYN). PDYN is processed into the opioid peptides $\alpha$-neoendorphin and dynorphins (Dyn) A and B; inhibitory neurotransmitters that function in pain signaling, stress-induced responses and addiction. Variants causing SCA23 mostly affect Dyn A, leading to loss of secondary structure and increased peptide stability. $P D Y N^{\mathrm{R} 212 \mathrm{~W}}$ mice express human PDYN containing the SCA23 variant p.R212W. These mice show progressive motor deficits from 3 months of age, climbing fiber (CF) deficits from 3 months of age, and Purkinje cell (PC) loss from 12 months of age. A mouse model for SCA1 showed similar CF deficits, and a recent study found additional developmental abnormalities, namely increased GABAergic interneuron connectivity and non-cell autonomous disruption of PC function. As SCA23 mice show a similar pathology to SCA1 mice in adulthood, we hypothesized that SCA23 may also follow SCA1 pathology during development. Examining $P D Y N^{\mathrm{R} 212 \mathrm{~W}}$ cerebella during development, we uncovered developmental deficits from 2 weeks of age, namely a reduced number of GABAergic synapses on PC soma, possibly leading to the observed delay in early phase CF elimination between 2 and 3 weeks of age. Furthermore, CFs did not reach terminal height, leaving proximal PC dendrites open to be occupied by parallel fibers (PFs). The observed increase in vGlut1 protein - a marker for PF-PC synapses - indicates that PFs indeed take over CF territory and have increased connectivity with PCs. Additionally, we detected altered expression of several critical $\mathrm{Ca}^{2+}$ channel subunits, potentially contributing to altered $\mathrm{Ca}^{2+}$ transients in $P D Y N^{\mathrm{R} 212 \mathrm{~W}}$ cerebella. These findings indicate that developmental abnormalities contribute to the SCA23 pathology and uncover a developmental role for PDYN in the cerebellum.
\end{abstract}

\section{INTRODUCTION}

Spinocerebellar ataxia type 23 (SCA23) is a late-onset, slowly progressive neurodegenerative disorder for which there is no available therapy. It is caused by pathogenic variants in $P D Y N$ and characterized by loss of neurons in the Purkinje cell (PC) layer, dentate nuclei and inferior olivary nuclei $(2,52)$. Patients suffer from gait ataxia, dysarthria, slowed saccades, ocular dysmetria, Babinski's sign and hyperreflexia. $P D Y N$ encodes the opioid precursor protein prodynorphin (PDYN), which is processed into the opioid peptides $\alpha$-neoendorphin and dynorphins (Dyn) A and B. These peptides normally function as inhibitory neurotransmitters in pain processing, stress-induced responses, and addiction (1, 9, 19, 43). Dyn A is also known to elicit non-opioid-mediated neurotoxic effects including allodynia, neuronal loss and paralysis $(19,22,53)$. It can cause cell death via the NMDA ( $N$-methyl- ${ }_{\mathrm{D}}$-aspartate) receptor (51), and elicit neurotoxic effects via the AMPA ( $\alpha$-amino-hydroxy-5-methylisoxazole-4propionate) receptor and acid-sensing ion 1a channels (44, 46). Additionally, we have shown that variants causing SCA23 affect the secondary structure of Dyn A, reducing its affinity with its natural $\kappa$-opioid receptor as well as peptide stability, leading to peptide aggregation (49).

We previously generated a transgenic mouse, the $P D Y N^{\mathrm{R} 212 \mathrm{~W}}$ mouse, overexpressing one copy of human $P D Y N$ containing the $\mathrm{p} . \mathrm{R} 212 \mathrm{~W}$ variant, and showed that they recapitulate features of SCA23 pathology, showing progressive gait deficits from 3 months of age and loss of motor coordination and balance at 12 months of age (47). Examination of the cerebella of these mice revealed a loss in climbing fiber (CF) height from 3 months of 
age, PC loss at 12 months of age and pathologically elevated levels of Dyn A peptide (47). Wild-type and $P D Y N^{\mathrm{WT}}$ mice, overexpressing one copy of wild-type human $P D Y N$, did not show consistent changes in these parameters (47).

CFs form a crucial component in synaptic plasticity, a process of great importance to the functioning of the cerebellum; it has long been thought to be the molecular mechanism underlying motor functioning and learning (18, 23, 24, 55). CFs and parallel fibers (PFs) are the excitatory inputs of the cerebellum, and synapse upon the singular output of the cerebellar cortex, the PC $(14,25)$. CFs form a crucial part of the cerebellar machinery, as they exert enormous control over the synaptic plasticity of the PFs $(18,24,30,54)$. In order to maintain the delicate balance of synaptic plasticity, both CFs and PFs have their own PC dendrite territories. CFs populate the proximal PC dendritic tree, whereas the PFs synapse upon the distal PC dendritic tree $(14,25)$. CFs and PFs compete for PC territory throughout life, and loss of one of these types of fibers leads to an increase in the other $(33,34)$. Alterations in components of this process lead to synaptic deficits in several mouse models suffering from ataxia and absence seizures $(28,39)$. The observed $\mathrm{CF}$ deficits in SCA23 are particularly interesting, as similar effects have been observed in other SCA types, including SCA1 (12, 13, 17, 40).

A recent publication demonstrated that in SCA1, stem cells hyperproliferate and preferably differentiate into GABAergic interneurons leading to increased inhibitory connections with PCs and non-cell autonomous PC dysfunction (15). As the CF deficits of SCA23 match those of SCA1 and preliminary data suggested early changes in the SCA23 cerebellum, we hypothesized that SCA23 may also follow this newly identified SCA1 pathology. Therefore, we studied $P D Y N^{\mathrm{R} 212 \mathrm{~W}}$ cerebella around the time of cerebellar circuit maturation, from 2 to 8 weeks of age. Interestingly, we found that in SCA23, GABAergic innervation shows reduced synapse connectivity. Here, we report the molecular changes observed in the developing $P D Y N^{\mathrm{R} 212 \mathrm{~W}}$ cerebellum, and propose an alternative disease model for SCA23.

\section{MATERIALS AND METHODS}

\section{Animals}

All animal experiments were performed according to the ethical guidelines of the Animal Welfare Committee of the University of Groningen, the Netherlands. The experimental protocols were approved by the Animal Welfare Committee of the University of Groningen. All efforts were made to reduce the number of animals and minimize their suffering. Transgenic mice were bred and genotyped as previously described (47), and housed with same-sex litter mates under standard conditions including environmental enrichment, with ad libitum access to food and water. Twelve animals were assigned to each group based on genotype, aged to 2, 3,
4 or 8 weeks of age and sacrificed humanely. Cerebellar vermes were dissected and snap-frozen in liquid nitrogen. In preparation for immunohistochemical stainings, mice were perfused with 4\% PFA, post-fixed for up to 24 hours in PFA, cryopreserved in $20 \%$ and $30 \%$ of sucrose solutions until saturated, and then frozen on dry ice. Researchers were blind to genotypes during collection of tissue and data collection.

\section{Immunohistochemistry}

Sectioning and staining were performed as described previously (47). The primary antibodies used were vesicular glutamate transporter 2 (vGlut2, rabbit, 1:1000, Synaptic Systems, Göttingen, Germany), vesicular GABA transporter (vGAT, rabbit, 1:1000, Synaptic Systems, Göttingen, Germany), glutamate decarboxylase 67 (GAD67, rabbit, 1:1000, Abcam, Cambridge, UK) and Calbindin (mouse, 1:500, Abcam, Cambridge, UK). The secondary anti-rabbit antibody was conjugated with Alexa Fluor 488, the antimouse antibody with Cy3 (both: donkey, 1:250, Jackson ImmunoResearch Laboratories, Suffolk, UK). Sections were imaged using an AxioObserver Z1 fluorescence microscope (Carl Zeiss, Oberkochen, Germany), an AxioScan Z1 scanning microscope (Zeiss, Oberkochen, Germany) and the images were analyzed using Fiji software (National Institutes of Health, http://fiji.sc/). The presented images were captured using a TCS SP8 confocal microscope (Leica, Wetzlar, Germany) and an AxioObserver Z1 compound microscope equipped with an ApoTome enabling structured illumination microscopy (Carl Zeiss, Oberkochen, Germany).

vGAT and vGlut2 vesicles on PC soma were quantified using a custom-made pipeline. First, PC soma were identified by creating masks using Calbindin stained images. These masks were subsequently used in the vGAT or vGlut 2 stained images to count puncta by determining local maxima in each PC soma. Per lobule, 4-7 images were collected and at least five PC soma were analyzed per image. CF height was analyzed by measuring both Calbindin and vGlut 2 staining height from the tip of the PC soma, and calculating the ratio. Per lobule 4-7 images were collected and analyzed. GAD67 stainings were performed without Calbindin co-staining. Here, fluorescence intensity was measured in the PC layer. Per lobule, 4-7 images were collected and analyzed.

\section{Reverse transcription PCR and quantitative real-time PCR}

Reverse transcription PCR and quantitative real-time PCR were performed as described previously (47). A full list of primers can be found in Table S1.

\section{Protein extraction and Western blotting}

Proteins were isolated from snap-frozen mouse vermis. Organs were homogenized in ice-cold RIPA buffer supplemented with a complete protease inhibitor cocktail (Roche, Basel, Switzerland) and PMSF (Sigma-Aldrich, Saint Louis, MO, USA). Samples were centrifuged for 15 minutes at 
$10000 \mathrm{rpm}$, and protein concentrations were determined using the Pierce BCA Protein Assay Kit (Thermo Scientific, Waltham, MA, USA). Equal amounts were loaded onto SDS-PAGE gels. After electrophoresis, the proteins were transferred to nitrocellulose membranes (Life Technologies, Carlsbad, CA, USA) and blocked with 5\% non-fat milk in Tris-buffered saline (TBS)-Tween. Blots were probed with primary antibodies against vGlut1 (rabbit, 1:1000, Synaptic Systems, Göttingen, Germany), vGlut2 (rabbit, 1:1000, Synaptic Systems, Göttingen, Germany) and actin (mouse, 1:5000, MP Biomedicals, Irvine, CA, USA). Secondary antibodies were conjugated with horseradish peroxidase (goat, 1:10 000, Jackson ImmunoResearch Laboratories, Suffolk, UK). Densitometric analysis was performed using ImageLab software (BioRad Laboratories, Hercules, CA, USA).

\section{Statistical analysis}

All data were normalized against 3-week-old control data and expressed as means \pm SEM. Two-way ANOVA was used to determine the significance of the observed differences between the genotypes and over time $(P<0.05$ was considered statistically significant).

\section{RESULTS}

\section{PDYNR212W cerebella show alterations in GABAergic connectivity}

Mice expressing human PDYN containing the p.R212W SCA23 variant $\left(P D Y N^{\mathrm{R} 212 \mathrm{~W}}\right.$ mice) suffer from loss of motor function and balance, coinciding with loss of $\mathrm{CF}$ height compared to control mice, as well as to mice expressing wild-type human PDYN (PDYN ${ }^{\mathrm{WT}}$ mice) (47). This pattern of findings for SCA23 is reminiscent of that seen for SCA1 $(12,13)$. Therefore, we hypothesized that SCA23 may also mirror other aspects of SCA1 pathology. Edamakanti et al found alterations in GABAergic signaling in SCA1 mice (15), leading us to investigate GABAergic signaling in $P D Y N^{\mathrm{R} 212 \mathrm{~W}}$ mice. We examined the inhibitory synapses from basket cells (BCs) on PC soma in the vermal lobules at 2, 3, 4 and 8 weeks of age, using the vesicular inhibitory amino acid transporter (vGAT) as a marker for inhibitory synapses and Calbindin as a marker for PCs (Figure 1A). $P D Y N^{\mathrm{R} 212 \mathrm{~W}}$ mice showed a reduced number of somatic inhibitory synapses at 2 weeks of age in lobules II, III, IV/V, IX and $\mathrm{X}$ as compared to $P D Y N^{\mathrm{WT}}$ and control mice, as well as in lobule $\mathrm{I}$ as compared to $P D Y N^{\mathrm{WT}}$ mice (Figure 1B). At 3 weeks of age, $P D Y N^{\mathrm{R} 212 \mathrm{~W}}$ lobule IV/V showed fewer synapses as compared to both $P D Y N^{\mathrm{WT}}$ and control, as well as $P D Y N^{\mathrm{R} 212 \mathrm{~W}}$ lobules $\mathrm{VI}$ and $\mathrm{X}$ as compared to control mice (Figure 1B). Lobules II, IV/V and $\mathrm{X}$ showed a decreased number of inhibitory synapses in $P D Y N^{\mathrm{R} 212 \mathrm{~W}}$ mice as compared to $P D Y N^{\mathrm{WT}}$ and control mice, as well as lobule $\mathrm{I}$ as compared to $P D Y N^{\mathrm{WT}}$ mice at 4 weeks of age (Figure $1 \mathrm{C}$ ). At 8 weeks of age, $P D Y N^{\mathrm{R} 212 \mathrm{~W}}$ mice showed fewer somatic synapses in lobules IV/V and VI as compared to both $P D Y N^{\mathrm{WT}}$ and control mice, in lobule II as compared to control mice and in lobules I and IX as compared to $P D Y N^{\mathrm{WT}}$ mice (Figure 1C). Taken together, these data indicate that SCA23 shows an opposite pathology to SCA1, as inhibitory synapses are lost on $P D Y N^{\mathrm{R} 212 \mathrm{~W}} \mathrm{PC}$ soma.

\section{CF development is disrupted in PDYNR212W mice}

As inhibitory connectivity plays a role in the early phase of CF synapse elimination by $\mathrm{BC}$ collaterals taking over somatic spines from weak CFs on the PCs, we next investigated CF-PC somatic synapses using vGlut2 as a marker for the CF-PC synapse and Calbindin as a marker for PCs (Figure 2A). Control and $P D Y N^{\mathrm{WT}}$ mice demonstrated normal early phase CF synapse elimination as demonstrated by significant reduction of $\mathrm{vGlut}^{+}$somatic puncta over time from 2 to 4 weeks of age (Figure 2B,C). $P D Y N^{\mathrm{R} 212 \mathrm{~W}}$ mice, however, do not show a significant reduction of these puncta between 2 and 3 weeks of age in lobules II, III, IV/V, VI and IX (Figure 2D). Additionally, in $P D Y N^{\mathrm{R} 212 \mathrm{~W}}$ mice, lobule VI does not show significantly fewer vGlut ${ }^{+}$ synapses from 3 weeks of age on and lobule $\mathrm{X}$ does not demonstrate any loss of CF somatic synapses (Figure 2D). While these data suggest that $P D Y N^{\mathrm{R} 212 \mathrm{~W}}$ mice do not start out with fewer somatic CF synapses, they point towards a disruption of early phase CF synapse elimination.

As CF development is a finely tuned process, these findings suggested that further CF development could also be affected. Using the same markers, we analyzed the reach of $\mathrm{CFs}$ by examining the $\mathrm{CF}$-PC synapses along the PC dendrites (Figure 3A). The PC dendrites of $P D Y N^{\mathrm{R} 212 \mathrm{~W}}$ mice showed a significantly reduced $\mathrm{CF}$ reach in vermal lobules I, II, III, VI/V, VI and IX at 2 weeks of age in comparison to those of $P D Y N^{\mathrm{WT}}$ and control mice (Figure 3B). The deficit persisted in these lobules and included lobule $\mathrm{X}$ at 3,4 and 8 weeks of age (Figure 3B,C). At 8 weeks of age, significance was lost in lobule IX (Figure 3C). CF reach did not decline between 2 and 8 weeks of age, but does eventually decrease by 12 months of age, as observed previously (47). Altogether, these data indicate disruption of normal $\mathrm{CF}$ development in $P D Y N^{\mathrm{R} 212 \mathrm{~W}}$ mice, specifically a delay in early phase $\mathrm{CF}$ synapse elimination and discontinued $\mathrm{CF}$ translocation, leading to a loss of the $\mathrm{CF}$ monopoly of the PC proximal dendrites.

\section{PDYNR212W mice display increased PF-PC connectivity}

On the distal PC dendritic tree, $\mathrm{CFs}$ and $\mathrm{PFs}$ are under intense competition for $\mathrm{PC}$ dendritic territory, and loss of $\mathrm{CF}$ synapses allows for an increase in PF synapses. This process, known as heterosynaptic competition, is employed during development and synaptic plasticity $(33,34)$. Given the striking loss of CF-PC synapses, we hypothesized that the number of PF-PC synapses may have increased. However, there is currently no suitable antibody available for a detailed histological quantification of vGlut1, the marker for PF-PC synapses. Therefore, we compared the protein levels of vGlut1 in the vermis of $P D Y N^{\mathrm{R} 212 \mathrm{~W}}$ mice to that of $P D Y N^{\mathrm{WT}}$ and 
A

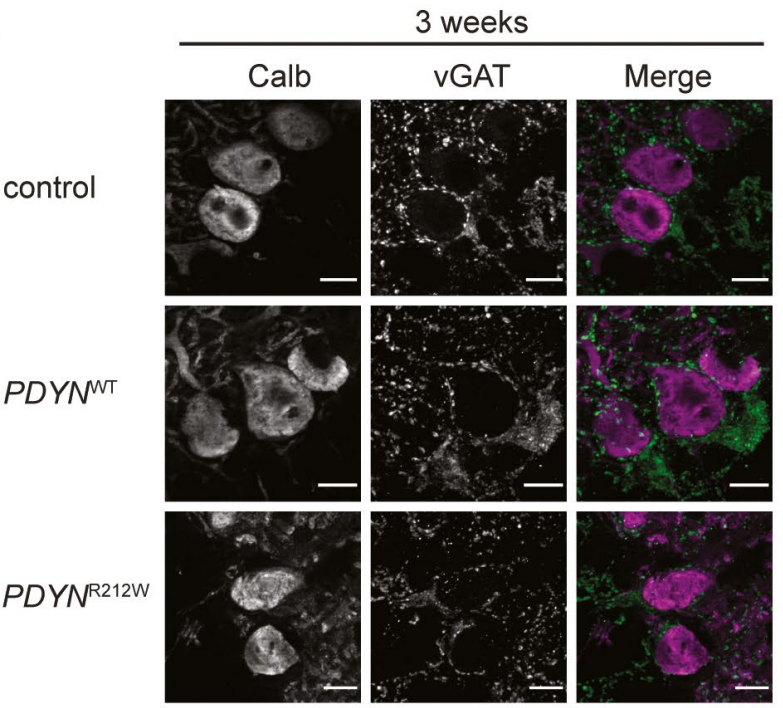

\section{B}

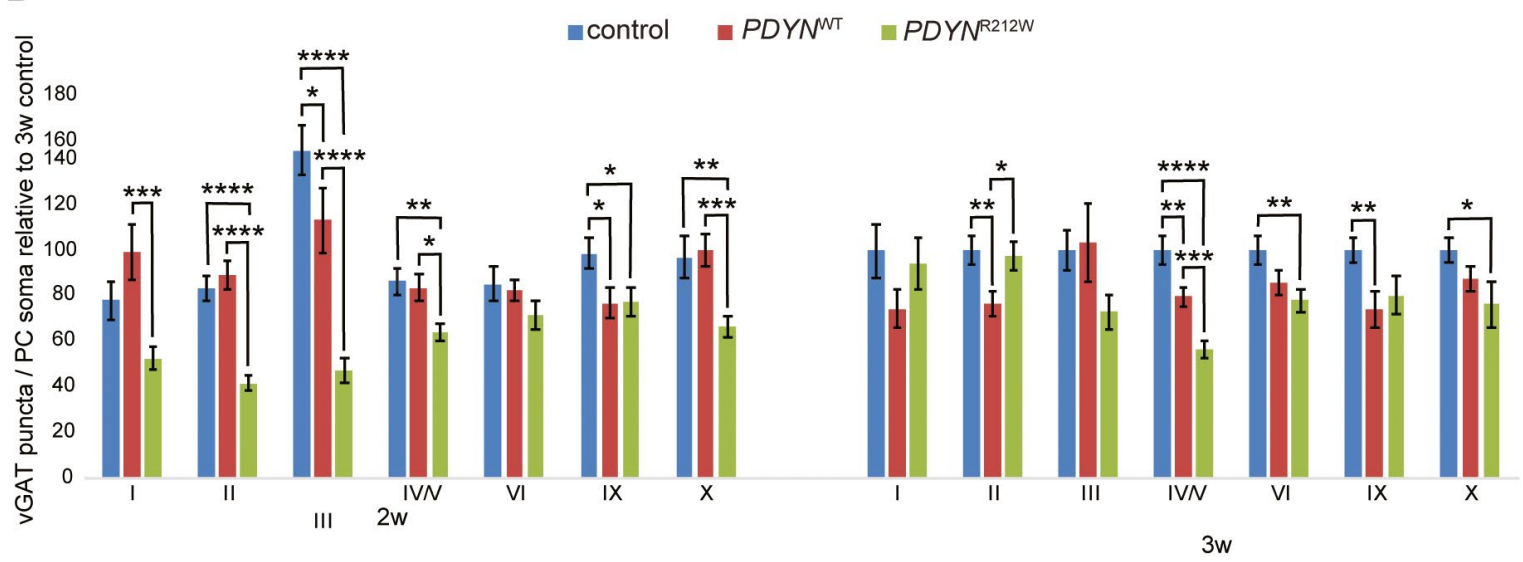

C

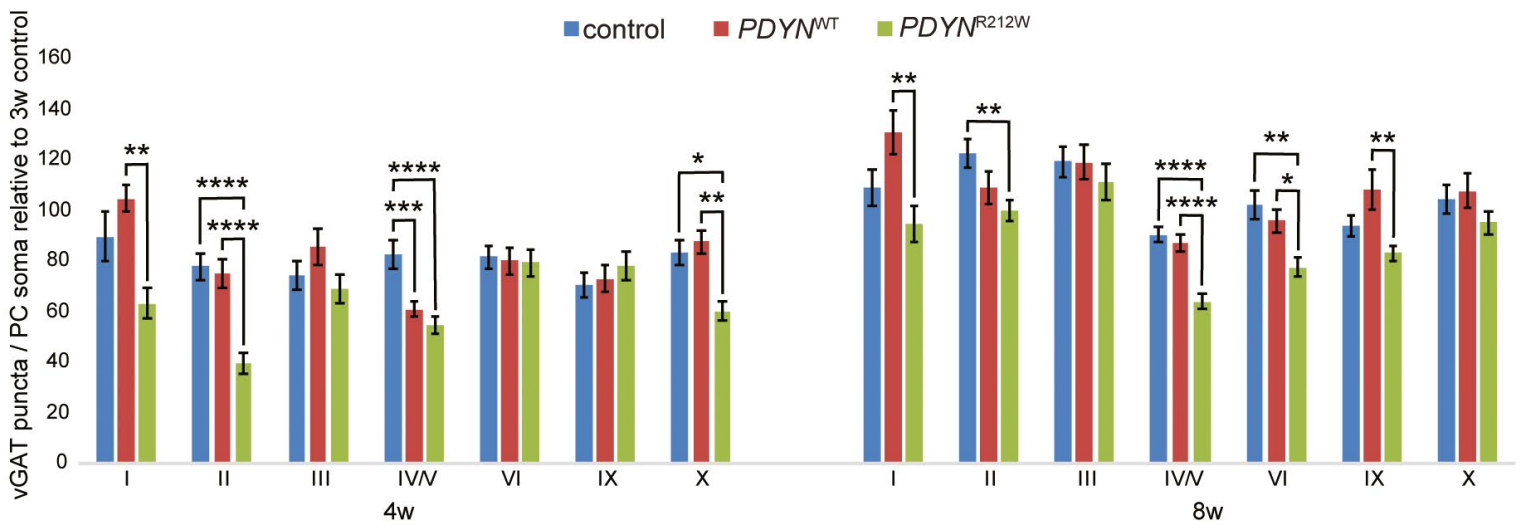

Figure 1. GABAergic innervation of Purkinje cells is reduced in $P D Y N^{R 212 W}$ mice. GABAergic presynaptic innervation of Purkinje cell (PC) soma in the vermis was determined by vGAT and Calbindin immunostaining, respectively. (A) Representative fluorescence images of vermal lobule IVN of control, PDYNNT and PDYN ${ }^{R 212 W}$ mice at 3 weeks of age stained with anti-calbindin antibody (magenta) and antivGAT (green) antibody. Scale bar $=20 \mu \mathrm{m}$. (B-C) Quantification of vGAT vesicles on PC somas, relative to control mice of 3 weeks of age, in vermal lobules I, II, III, IVN, VI, IX and $X$ of control, PDYN ${ }^{N T}$ and PDYN ${ }^{R 212 W}$ mice of $2,3,4$ and 8 weeks of age ( $n=5$ cells per section per lobule [minimum 20 cells] per genotype). PDYN ${ }^{\mathrm{R} 212 \mathrm{~W}}$ mice show reduced amounts of somatic vGAT vesicles early in development. ${ }^{*} P<0.05,{ }^{* *} P<0.01,{ }^{* *} P<0.001$ and ${ }^{* * * *} P<0.0001$. [Colour figure can be viewed at wileyonlinelibrary.com] 
A

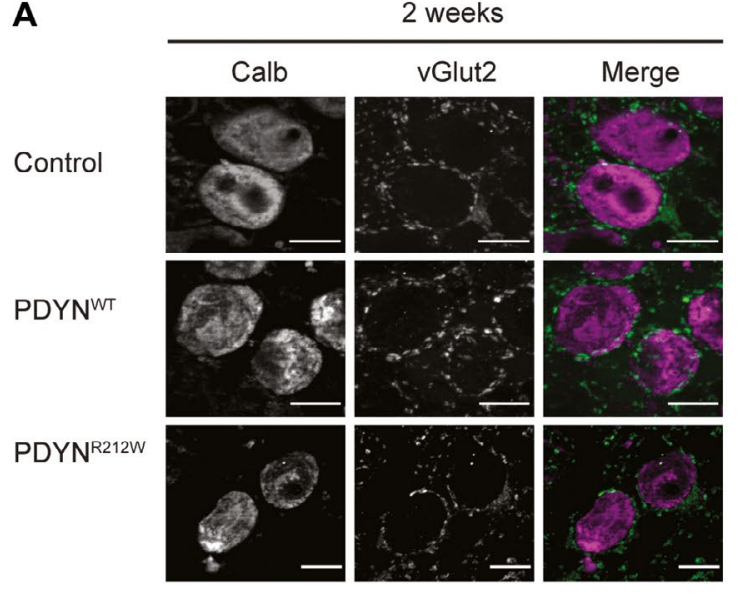

2 weeks

3 weeks

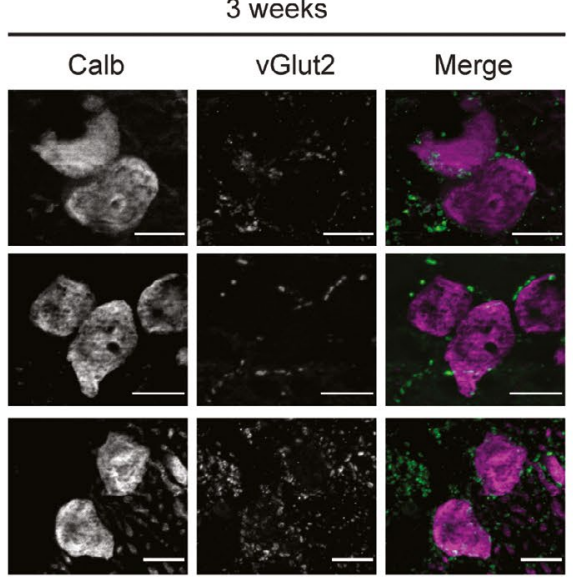

B

control

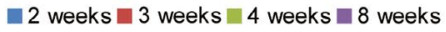

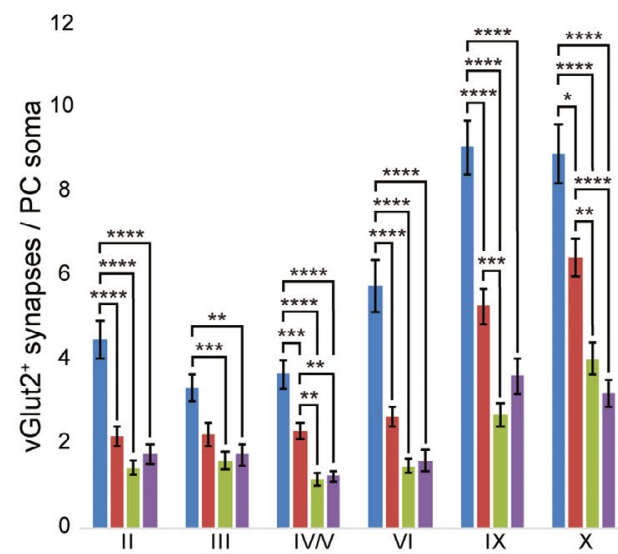

D

PDYN ${ }^{\mathrm{R} 212 \mathrm{~W}}$

$\square 2$ weeks $\square 3$ weeks $\square 4$ weeks $\square 8$ weeks

12

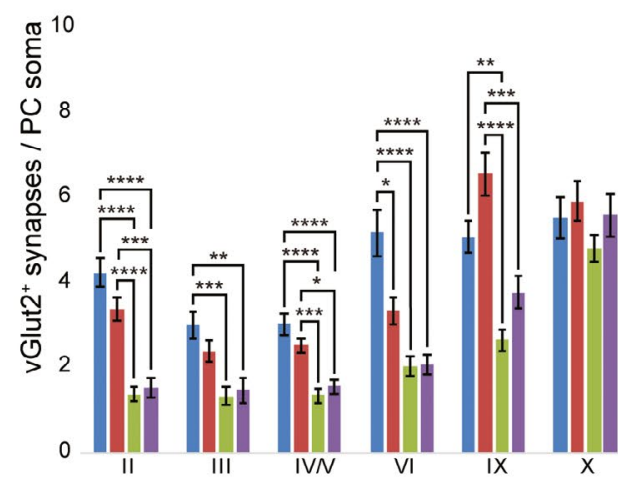

Figure 2. Climbing fiber synapse elimination is impaired in PDYNR212W mice. The presynaptic innervation of Purkinje cells (PC) by climbing fibers (CF) in the vermis during development was assessed by Calbindin and vGlut2 immunostaining, respectively. (A) Representative fluorescence images of vermal lobule $X$ of control, PDYNWT and $P D Y N^{R 212 W}$ mice at 2 and 3 weeks of age stained with anti-Calbindin (magenta) and anti-vGlut2 (green) antibody. Scale bar $=20 \mu \mathrm{m}$ (B-D) Quantification of the vGlut2 puncta per PC soma in vermal lobules II, III,

\section{C}

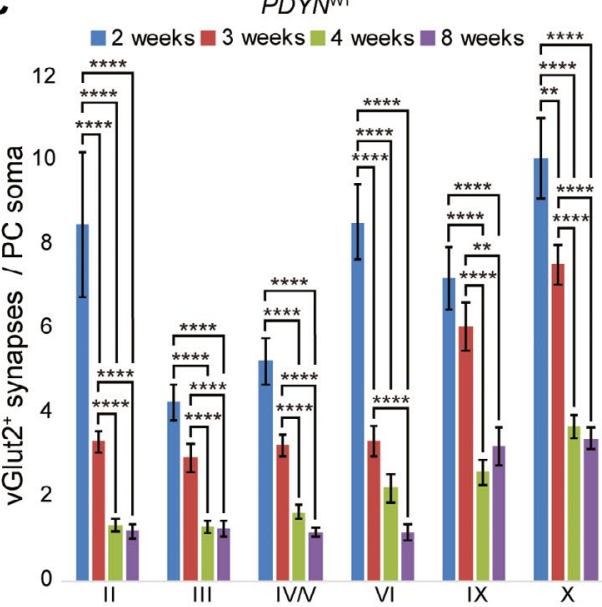


A 3 weeks
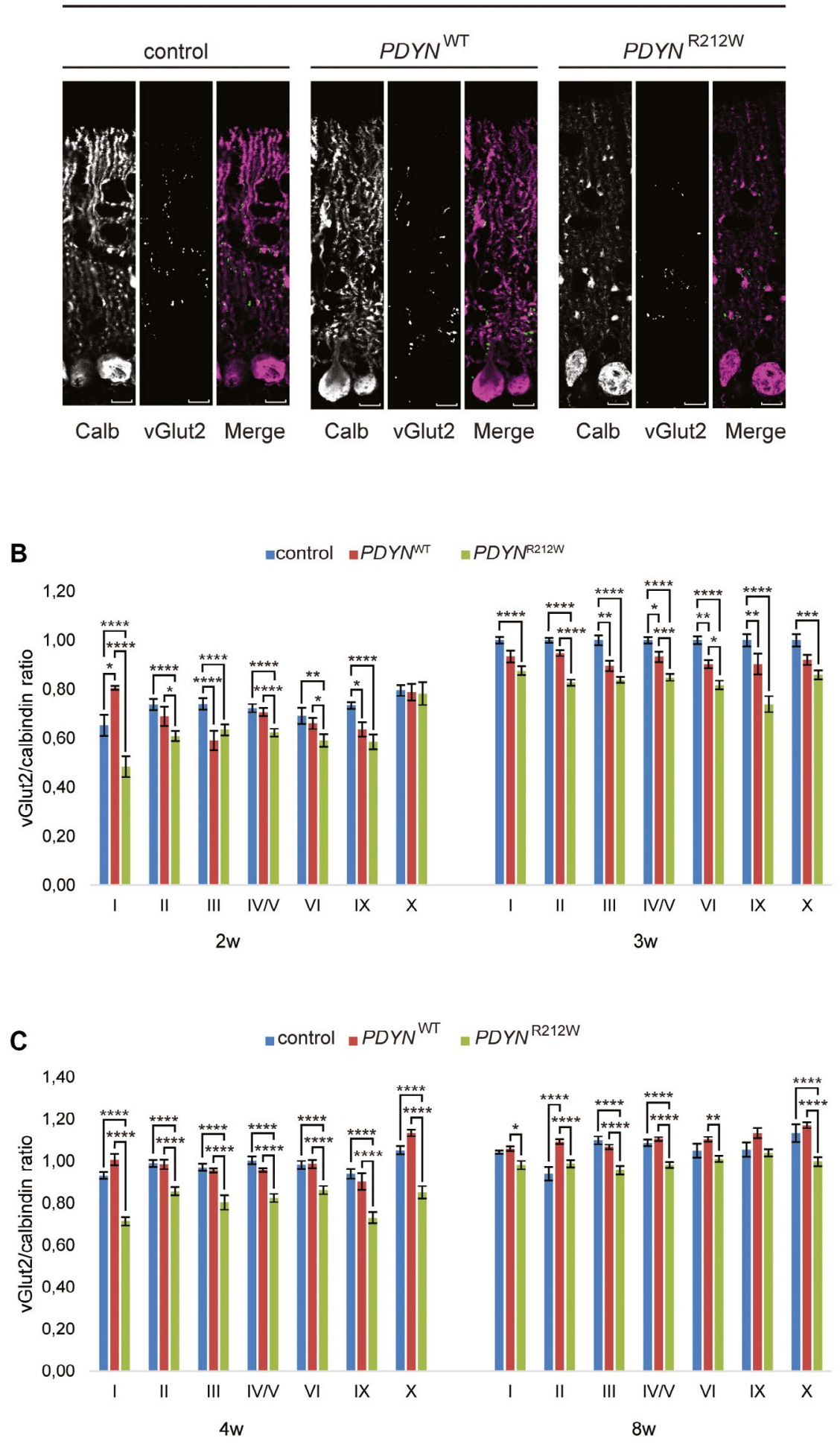

Figure 3. PDYNR212W mice show developmental climbing fiber deficits. The distribution of climbing fibers (CF) over the Purkinje cell (PC) dendritic tree in the vermis was assessed by vGlut2 and Calbindin immunostaining, respectively. (A) Representative confocal images of vermal lobule IVN of control, PDYN and $P D Y N^{R 212 W}$ mice at 3 weeks of age stained with anti-Calbindin (magenta) and anti-vGlut2 (green) antibody. (B-C) Quantification of the relative height of vGlut2 compared to Calbindin staining in vermal lobules I, II, III, IVN VI, IX and X of control,
PDYNT and PDYNR212W mice of 2 and 3 weeks of age ( $n=4-7$, per genotype). At 2 weeks of age, $P D Y N^{R 212 W}$ mice show significant loss of CF-PC synapses in all lobules except lobule X. At 3 weeks of age, lobule $X$ also displayed reduced CF-PC synapses in $P D Y N^{R 212 W}$ mice. All lobules showed reduced CF-PC synapses in PDYN R212W mice at 4 weeks of age, while at 8 weeks of age, significance in lobule IX was lost. ${ }^{*} P<0.05$, ${ }^{*} P<0.01,{ }^{* *} P<0.001$ and ${ }^{* * *} P<0.0001$. [Colour figure can be viewed at wileyonlinelibrary.com] 


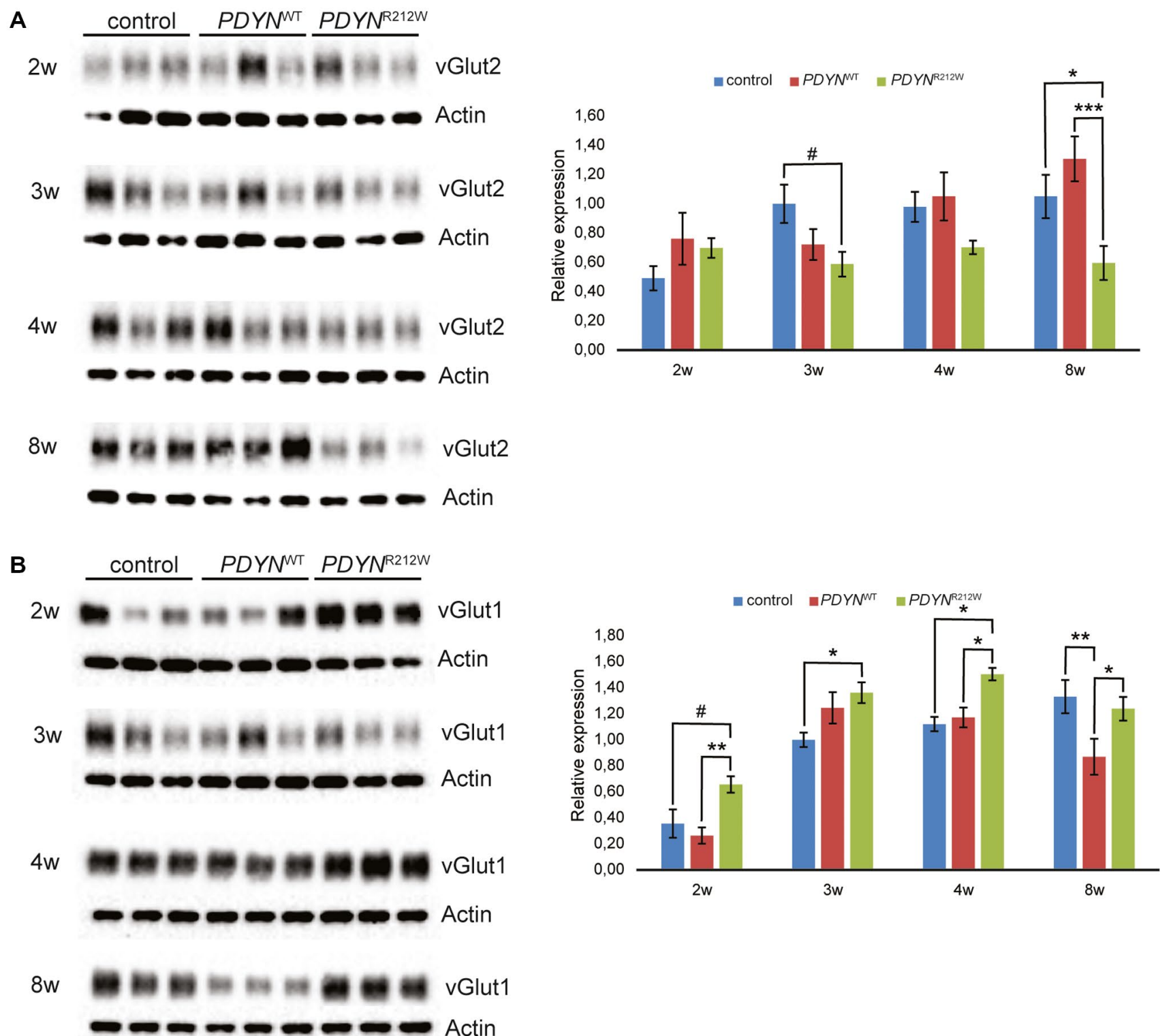

Figure 4. Altered vGlut1 protein levels indicate developmental abnormalities in the vermis of PDYN ${ }^{212 W}$ mice. $(A, B)$ The left panel shows representative immunoblots of control, PDYN $N^{N T}$ and PDYN R212W vermal protein lysates, stained or vGlut1 and actin. The right panel shows quantification of these immunoblots using ImageLab software.

control mice. Since vGlut1 and -2 are highly expressed in the cerebellar granule layer, we first ascertained whether we could see a change in vGlut2 protein levels representing the loss of CF-PC synapses by determining vGlut 2 protein levels in whole vermis protein lysate. At 8 weeks of age, we observed the expected reduction of overall vGlut2 levels in $P D Y N^{\mathrm{R} 212 \mathrm{~W}}$ cerebella (Figure 4A). Although this reduction was only significant at 8 weeks of age, we were able to observe changes in overall vGlut 2 protein level, indicating that changes in vGlut1 protein levels point to changes in PF-PC synapse count. The vGlut1 protein levels in $P D Y N^{\mathrm{R} 212 \mathrm{~W}}$ vermis were significantly increased at 2,3 and

vGlut1 protein levels were increased in $P D Y N^{R 212 W}$ at 2, 3 and 4 weeks compared with control mice and at 2, 4 and 8 weeks of age compared with PDYN mice ( $\mathrm{n}=3$ per genotype). \# 0.10>p $p 0.05,{ }^{*} P<0.05$, ${ }^{*} P<0.01$. [Colour figure can be viewed at wileyonlinelibrary.com]

4 weeks of age compared to control vermis, and at 8 weeks of age compared to $P D Y N^{\mathrm{WT}}$ vermis (Figure 4B). The elevated levels of vGlutl suggest that PFs have increased their synapse numbers in the vermis of $P D Y N^{\mathrm{R} 212 \mathrm{~W}}$ mice, as CFs cannot reach terminal height to populate their natural PC dendritic territory.

\section{Reduced GAD67 expression could indicate internal changes in PDYNR212W PCs}

As both GABAergic and glutamatergic inputs are altered in $P D Y N^{\mathrm{R} 212 \mathrm{~W}}$ mice, we hypothesized that perhaps $\mathrm{PCs}$ 
adapted internal changes to counteract these alterations. Therefore, we determined the expression of glutamate decarboxylase 67 (GAD67), the main enzyme used by PCs to convert glutamate into GABA. Using GAD67 immunostaining, we determined expression levels by measuring fluorescence intensity in the PC layer of control, $P D Y N^{\mathrm{WT}}$ and $P D Y N^{\mathrm{R} 212 \mathrm{~W}}$ mice (Figure 5A). We observed a loss of GAD67 in $P D Y N^{\mathrm{R} 212 \mathrm{~W}} \mathrm{PCs}$ at 2, 3 and 4 weeks of age as compared to control mice and at 4 weeks as compared to $P D Y N^{\mathrm{WT}}$ mice (Figure 5B). These data suggest that $P D Y N^{\mathrm{R} 212 \mathrm{~W}} \mathrm{PCs}$ produce less GABA, which could be a reaction to the lost input from basket cells and/or CFs, possibly to normalize their impact on cerebellar nuclei neurons.

\section{Changes in NMDA receptor subunits suggest altered $\mathrm{Ca}^{2+}$ signaling}

Loss of vGlut2 has been shown to impair glutamatergic transmission (20), and we have previously demonstrated changes in NMDA receptor Grin2a subunit expression in $P D Y N^{\mathrm{R} 212 \mathrm{~W}}$ mice at 3 months of age (47). Therefore, we determined the mRNA expression levels of the Grin2 NMDA receptor subunits in the vermis of 2-, 3-, 4- and 8-week-old $P D Y N^{\mathrm{WT}}, P D Y N^{\mathrm{R} 212 \mathrm{~W}}$ and control mice. The expression levels of these subunits were relatively low and no significant alterations were detected in $P D Y N^{\mathrm{R} 212 \mathrm{~W}}$ mice (Figure S1A). We also determined the mRNA expression levels of the remaining NMDA receptors subunits Grin1, Grin3a and $-b$. No alterations in Grin1, Grin3a and $-b$ subunit expression were observed in 2-, 3- and 8-week-old $P D Y N^{\mathrm{R} 212 \mathrm{~W}}$ mice (Figure 6A). However, the expression of Grinl was significantly increased at 4 weeks of age in $P D Y N^{\mathrm{R} 212 \mathrm{~W}}$ mice as compared to control and $P D Y N^{\mathrm{WT}}$ mice (Figure 6A), while the inhibitory subunits Grin $3 a$ and $-b$ displayed significantly decreased expression (Figure 6A). Since Grin1 is the essential subunit for surface expression of NMDA receptors (31), it is possible that at 4 weeks of age, $P D Y N^{\mathrm{R} 212 \mathrm{~W}}$ mice have increased surface expression of NMDA receptors. Taken together, in 4-week-old $P D Y N^{\mathrm{R} 212 \mathrm{~W}}$ mice, when NMDA receptors are expressed at $\mathrm{PF}$ - and CF-PC synapses in wildtype mice (56), the expression of crucial NMDA receptor subunits is altered, potentially causing altered $\mathrm{Ca}^{2+}$ signaling.

\section{VGCC dysregulation may be evidence of a compensatory mechanism for PDYN-R212W expression}

As $P D Y N^{\mathrm{R} 212 \mathrm{~W}}$ mice display alterations in the development of crucial PC inputs and NMDA receptor subunit expression is affected, we hypothesized that the expression of voltage-gated $\mathrm{Ca}^{2+}$ channels (VGCCs) may also be affected. Cav2.1, a VGCC encoded by Cacnala, the SCA6 disease gene (60), is crucial for proper $\mathrm{CF}$ maturation and regulates the expression of several genes involved in PC development $(11,26,33,38)$. Based on these prior findings, dysregulation of Cacnala could potentially underlie the observed $\mathrm{CF}$ and PC deficits (28, 39), and ultimately ataxia (3, 7, 16, 28, 29). To investigate whether $P D Y N^{\mathrm{R} 212 \mathrm{~W}}$ mice exhibit altered $\mathrm{Ca}^{2+}$ signaling via VGCCs, we assessed the mRNA expression levels of the cerebellar VGCC subunits Cacnala and $-c$, Cacna2d 2 and -3, Cacnb2 and -4 and Cacng2 and -7 in the vermis of $P D Y N^{\mathrm{WT}}, P D Y N^{\mathrm{R} 212 \mathrm{~W}}$ and control mice. The mRNA level of Cacnala was significantly increased at 3, 4 and 8 weeks of age in $P D Y N^{\mathrm{R} 212 \mathrm{~W}}$ mice (Figure $6 \mathrm{~B}$ ). A similar effect was observed for Cacnalc, its expression was increased at 2, 4 and 8 weeks of age in $P D Y N^{\mathrm{R} 212 \mathrm{~W}}$ mice (Figure 6B). At 8 weeks of age, the expression of
A

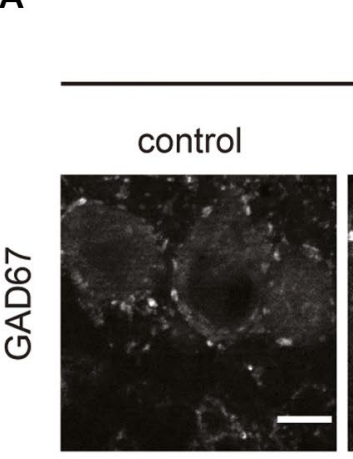

3 weeks

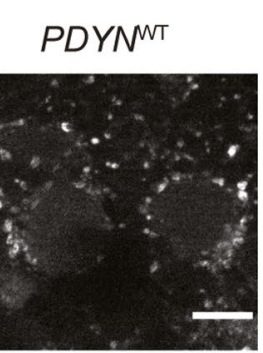

B

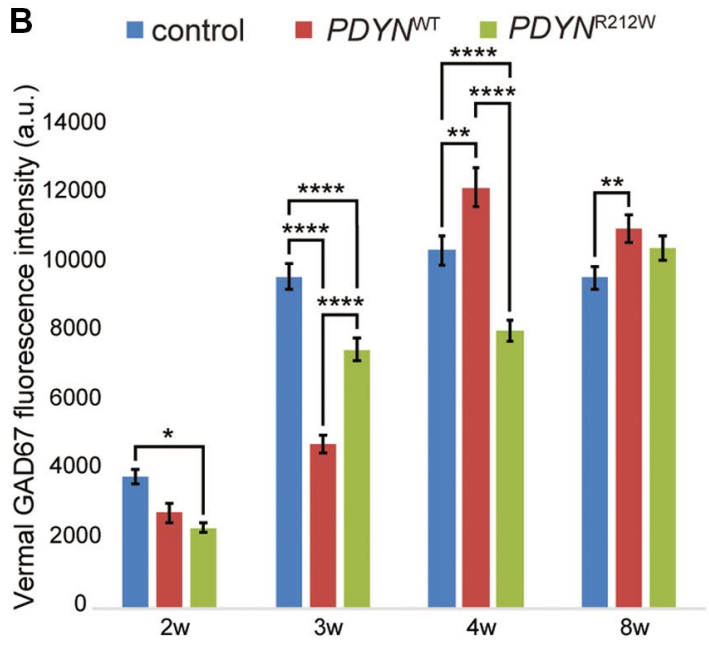

Figure 5. PDYN ${ }^{R 212 W}$ mice show reduced GABAergic transmission. The GABAergic inhibitory transmission by interneurons in the vermis was assessed with GAD67 immunostaining. (A) Representative fluorescence images of vermal lobule IVN of control, PDYN ${ }^{W T}$ and $P D Y N^{R 212 W}$ mice at 3 weeks of age stained with anti-GAD67 antibody. Scale bar $=20 \mu \mathrm{m}$ (B) Quantification of the relative fluorescence intensity of GAD67 in the total vermis of control, PDYNWT and PDYN ${ }^{\mathrm{R} 212 \mathrm{~W}}$ mice of 2, 3, 4 and 8 weeks of age $(n=20-30$ images per genotype, minimum 24 measurements). PDYNR212W vermis shows reduced GAD67 fluorescence intensity as compared to control mice at 2,3 and 4 weeks of age. ${ }^{*} P<0.05,{ }^{*} P<0.01$ and ${ }^{*} * * *<0.0001$. [Colour figure can be viewed at wileyonlinelibrary.com] 
both Cacna2d2 and -3 was upregulated in $P D Y N^{\mathrm{R} 212 \mathrm{~W}}$ vermis (Figure 6B), which was also observed for Cacnb2 and -4 (Figure 6C). Additionally, Cacnb2 expression was also increased at 2 weeks of age, and Cacnb4 at 4 weeks of age (Figure 6C). As these last four subunits are auxiliary subunits, regulating the function of Cacnala and Cacnalc, the observed increases could be a response to the increased Cacnala and Cacnalc mRNA levels. Cacng2 and Cacng7 mRNA expression was increased at 8 and 4 weeks of age, respectively (Figure 6C). Since Cacng2 and Cacng7 primarily
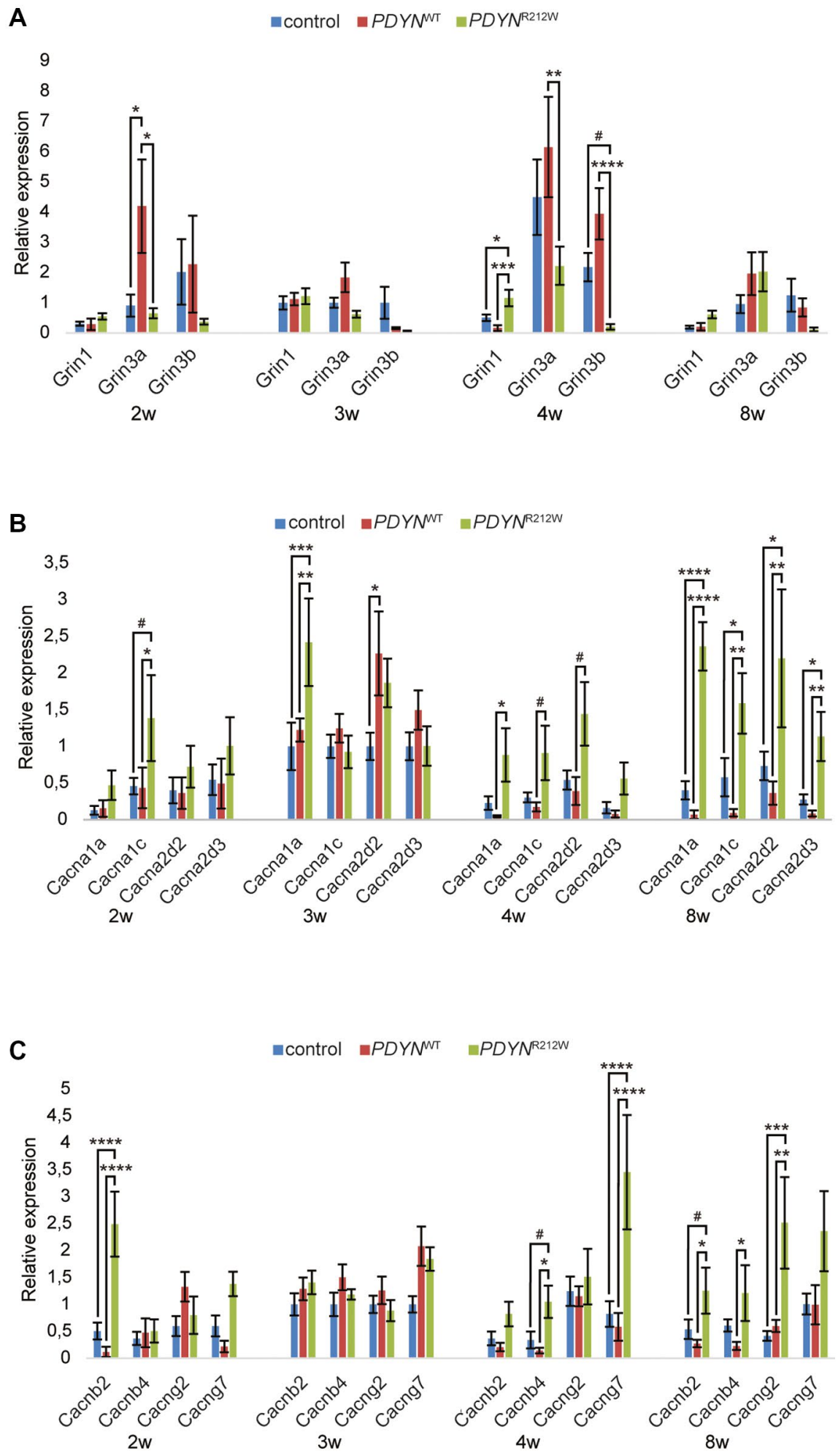
Figure 6. Altered expression of $\mathrm{Ca}^{2+}$ channel subunits suggests a compensatory mechanism in PDYNR212W mice. Quantification of RT-qPCR data from 2, 3, 4 and 8-week-old cerebella from control, PDYN and PDYN ${ }^{R 212 W}$ mice ( $n=6$, per genotype). (A) At 4 weeks of age, Grin 1 showed elevated expression in $P D Y N^{R 212 W}$ as compared to PDYN ${ }^{W T}$ and control mice. Simultaneously, Grin3a and $-b$ expression was significantly reduced in these mice as compared to control and PDYN ${ }^{N T}$ mice, respectively. For Grin3a, expression was increased in PDYN ${ }^{N T}$ compared with control and $P D Y N^{R 212 W}$ mice, but this was likely due to expression of PDYN-WT. (B) Cacna1a expression was elevated at 3, 4 and 8 weeks of age in $P D Y N^{R 212 W}$ as compared to control and PDYN ${ }^{W T}$ mice, while Cacna1c expression was increased at 2, 4 and 8 weeks of age. In 3, 4 and 8-weekold PDYN ${ }^{R 212 \mathrm{~W}}$ mice, Cacna2d2 was elevated, and at 8 weeks of age, Cacna2a3 expression was elevated in PDYN ${ }^{R 212 \mathrm{~W}}$ mice as well compared with control and PDYN mice. (C) Cacnb2 expression was increased at 2 and 8 weeks of age in PDYN R212W mice compared to both control and PDYNTT mice, while Cacnb4 expression was enhanced at 4 weeks of age. For Cacng2 and Cacng7, expression was elevated at 8 and 4 weeks of age, respectively. \# $0.10>p>0.05,{ }^{*} P<0.05,{ }^{*} P<0.01,{ }^{*}{ }^{*} P<0.001$ and **** $P<0.0001$. [Colour figure can be viewed at wileyonlinelibrary.com] regulate trafficking, localization and biophysical properties of AMPA receptors $(6,58)$, we also studied the mRNA levels of Grial-4. However, we found no correlation with the expression levels of Cacng2 and Cacng7 (Figure S1B). These data demonstrate that Cav2.1, a key player in CF maturation, is markedly upregulated in $P D Y N^{\mathrm{R} 212 \mathrm{~W}}$ vermis around the time of $\mathrm{CF}$ maturation. We therefore suggest that dysregulated expression of crucial VGCCs and their auxiliary subunits contributes to the $\mathrm{CF}$ maturation deficits and loss of CF-PC connectivity in $P D Y N^{\mathrm{R} 212 \mathrm{~W}}$ cerebella.

\section{DISCUSSION}

Our data are the first to demonstrate a neurodevelopmental role for PDYN, as we observed cerebellar developmental deficits in $P D Y N^{\mathrm{R} 212 \mathrm{~W}}$ mice that include loss of GABAergic connectivity, disrupted CF development, increased PF-PC connectivity and dysregulation of key VGCC subunits that are involved in $\mathrm{CF}$ maturation between 2 and 8 weeks of age. Moreover, the loss of CF-PC synapses persisted up to 12 months of age, and likely contributes to PC degeneration (47). The alterations in the maturation and number of CF-PC synapses, the number of BC-PC synapses and the expression of vGlut2 and vGlut1 support our hypothesis that developmental deficits in synaptic wiring contribute to motor dysfunction and ataxia. While one study found development of the brain was not affected in Pdyn knockdown mice, the cerebellum was not studied in detail (32). Our evidence leads us to propose that PDYN has different functions in the cerebrum versus the cerebellum, and that, in the cerebellum, it plays key roles in development.

$\mathrm{BCs}$ innervate the PC soma and form the pinceau on the PC initial axonal segment, inhibiting PC firing. A recent publication demonstrated that the loss of stellate and basket cell GABAergic transmission does not affect PC dendritic tree development and maintenance (5). However, Brown et al also demonstrated that stellate and basket cells cooperate to establish the correct rate and pattern of simple and complex spike firing of PCs in vivo, and that loss of $\mathrm{BC}$ inhibition increased $\mathrm{PC}$ simple spike firing, while it decreased the $\mathrm{PC}$ complex firing rate (5). The loss of $\mathrm{vGAT}^{+}$somatic synapses in $P D Y N^{\mathrm{R} 212 \mathrm{~W}}$ vermis suggests that SCA23 PCs suffer from reduced inhibition leading to changes in simple and complex spike firing rates as well as reduced synchronous firing of PC zones, altering cerebellar output and leading to motor dysfunction and ataxia $(21,27,41)$. The observed loss of GAD67 likely contributes to this altered cerebellar output. Notably, reduced levels of GAD67 mRNA in PCs have been observed in the cerebella of people with autism (59). Additionally, BC-PC synapse formation is critical for early phase CF synapse elimination, as BC collaterals take over PC somatic spines from CFs (26). Therefore, the absence of BC-PC synapses may underlie the observed delay in early CF synapse elimination. Nakayama et al. have shown that diazepam, a $\mathrm{GABA}_{\mathrm{A}}$ receptor sensitizer, can restore impaired $\mathrm{CF}$ maturation due to altered GABAergic transmission (37). Hence, we put forward the malformation of GABAergic innervation as a possible therapeutic target for SCA23.

Loss of vGlut2 in the vermis of $P D Y N^{\mathrm{R} 212 \mathrm{~W}}$ mice supports a developmental deficit in the cerebellum, in line with findings showing developmental roles for vGlut2 in the hippocampus (20). A vGlut2 conditional knockout mouse displayed increased open-field exploratory behavior and impaired spatial learning and memory, a phenotype similar to that of NMDA receptor knockdown mice (20, 42). Deficiency of vGlut2 led to reductions of evoked glutamate transmission, neurotransmitter release probability and long-term depression at hippocampal CA3-CA1 synapses during postnatal development. This led to a loss of arborization of the dendritic tree and reductions in the number of dendritic spines in adult mice, suggesting widespread alterations in synaptic connectivity (20). We hypothesize that vGlut2 serves a similar purpose in the cerebellum, with deficiency leading to reduced glutamatergic transmission and, consequently, disturbed $\mathrm{Ca}^{2+}$ signaling and malformation of PC dendrites. This hypothesis is strengthened by our previous observation that cultured neurons of $P D Y N^{\mathrm{R} 212 \mathrm{~W}}$ cerebella show reduced neuronal excitability (47), which could be caused by the loss of vGlut2 expression.

$P D Y N^{\mathrm{R} 212 \mathrm{~W}}$ mice displayed elevated vGlut1 levels at 2, 3 and 4 weeks of age, which suggests that PFs in these animals extended their innervation territory on PCs to include more proximal dendrites. The timing of increased vGlut1 expression coincides with late phase $\mathrm{CF}$ synapse elimination, a process critically dependent on normal PF-PC synapse formation (26), suggesting that aberrant PF-PC synapse formation supports the malformation of CFs. A cause of aberrant PF-PC synapse formation could be the increased expression levels of Cacnala, which encodes Cav2.1, at 3, 4 and 8 weeks of age. Increased expression of this subunit 

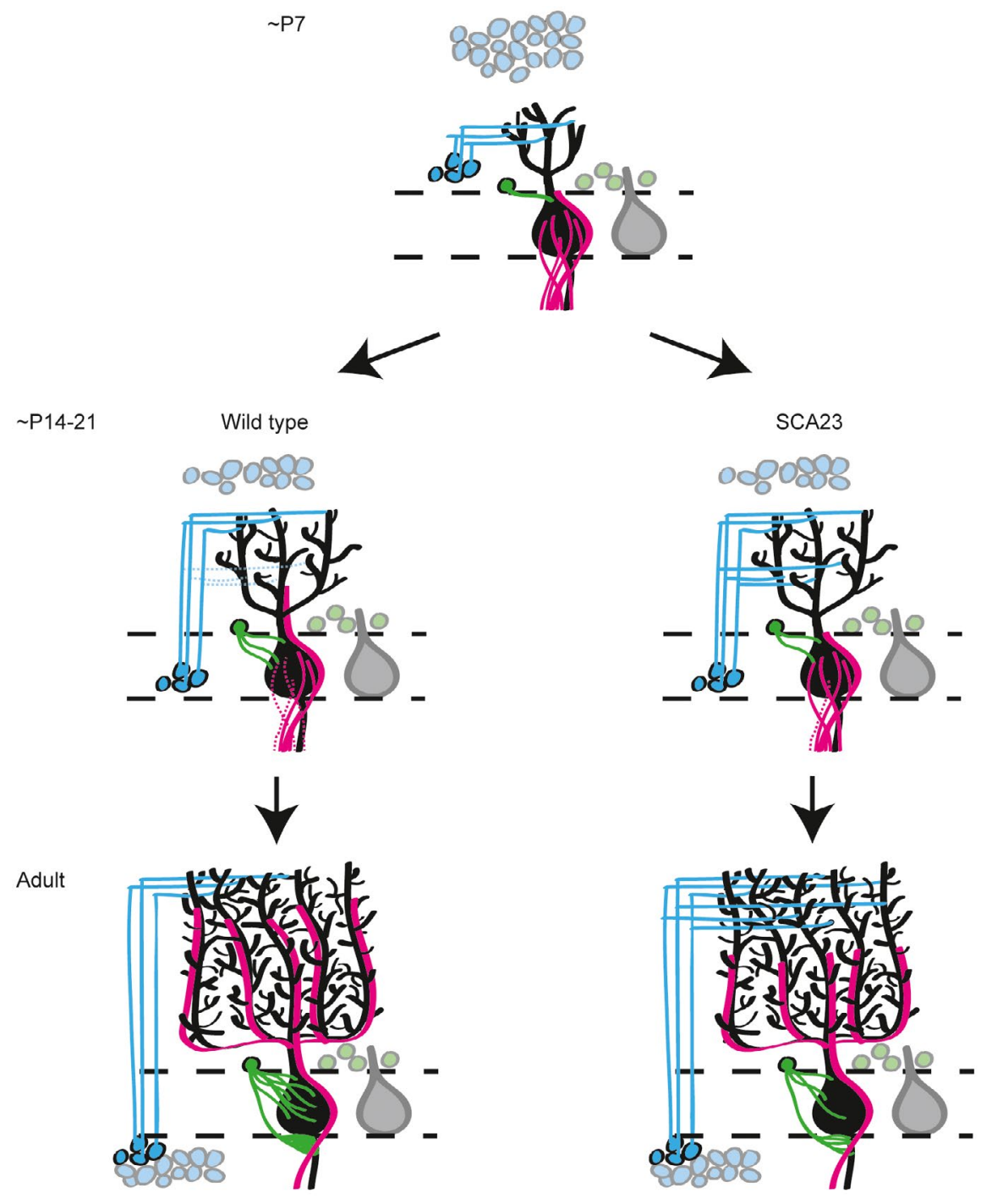

- Balanced synaptic plasticity
- Normal $\mathrm{Ca}^{2+}$ signalling

- Normal $\mathrm{Ca}^{2+}$ signalling

- Reduced BC-PC synapses

- Reduced CF-PC synapses

- Increased PF-PC synapses

- Altered $\mathrm{Ca} 2+$ signalling

- Impaired motor output

Figure 7. Cerebellar developmental abnormalities underlie SCA23. Under normal conditions, cerebellar development progresses in highly regulated, clear phases (left panels). In SCA23 cerebella, we have observed several disruptions of cerebellar development. First, basket cells (in green) form fewer somatic synapses in SCA23 cerebella. Second, climbing fibers (CFs, in pink) display a delay in CF synapse elimination, as well as a failure to reach terminal height to innervate the

may affect heterosynaptic competition between PFs and CFs and distal extension of CFs (33). However, as Cacnala is elevated from 3 weeks of age, the increase in vGlut1 at 2 weeks of age could be caused by the loss of vGlut2 at that time. Cacnala dysregulation may also disrupt $\mathrm{CF}$ maturation, distal $\mathrm{CF}$ extension and $\mathrm{Ca}^{2+}$ signaling, as Cav2.1 proximal Purkinje cell (PC) dendrites. These deficits likely lead to the third disruption, an increase in parallel fiber-PC synapses (in blue). These developmental abnormalities, combined with our other findings, very likely lead to altered $\mathrm{Ca}^{2+}$ signaling and, consequently, impaired motor output and ataxia. [Colour figure can be viewed at wileyonlinelibrary. com]

plays crucial roles in these processes $(8,33,56)$. Moreover, the C-terminal tail of the channel functions as a transcription factor, coordinating the expression of genes involved in PC development (11). PC loss has not been observed until 12 months of age (47).Therefore, altered cerebellar development may lead to PC dysfunction before 12 months 
of age. Increased expression of Cacnalc, encoding Cav1.2, very likely contributes to the SCA23 pathology, as it plays significant roles in neuronal activity and survival, dendritic development, synaptic plasticity, memory formation and learning $(4,35,36,50,57)$. Additionally, an intronic variant in $C A C N A 1 C$ was recently proposed to be disease-causing in a Chinese family with autosomal dominant cerebellar ataxia (10), suggesting a role for Cacnalc in the pathology of ataxias. Furthermore, as a loss of vGlut2 could lead to reduced glutamatergic transmission, and consequently, disturbed $\mathrm{Ca}^{2+}$ signaling, the increases in expression of these VGCCs and their auxiliary subunits could be a compensatory mechanism for these changes. Altered expression of other $\mathrm{Ca}^{2+}$ channel subunits including Cacng2, Cacng7, Grin1, Grin3a and Grin $3 b$ further hint towards dysregulation of $\mathrm{Ca}^{2+}$ signaling, however, due to the absence of consistent changes, we cannot draw strong conclusions from these data.

It has long been established that the loss of CF input causes PCs to malfunction, as CFs play a dual role in cerebellar functioning; 1) control of synaptic plasticity at dendritic PC synapses, and 2) generating the distinct complex spike output in the PC axon, and motor learning and performance crucially depend on them (48). Additionally, CF deficits have been observed in other SCA types as well, including SCA1 $(12,13,17,45)$. The arrested development of $\mathrm{CFs}$ in $P D Y N^{\mathrm{R} 212 \mathrm{~W}}$ mice, therefore, likely underlies the ataxic phenotype (47). Interestingly, while the SCA23 pathology may mirror that of SCA1 in adulthood, the underlying developmental deficits oppose each other. In SCA1, Edamakanti et al. found hyperproliferation of stem cells that preferentially differentiated into GABAergic interneurons, leading to increased GABAergic interneuron connectivity and non-cell autonomous disruption of PC function (15). As discussed above, there could be several explanations as to why CFs develop abnormally in SCA23. We believe that the most likely culprit is the loss of GABAergic connectivity that should be provided to PCs by the BCs, as this is the earliest disruption in normal cerebellar development that we have detected (Figure 7). How expression of PDYN-R212W leads to dysfunction of BCs should be studied further.

In conclusion, the early loss of BC-PC and, consequently, CF-PC synapses plays a crucial role in the neuropathology of SCA23. We previously hypothesized that an increase in intracellular $\mathrm{Ca}^{2+}$ underlies the SCA23 pathology (47). With the evidence presented here, it now appears more likely that the disturbance in $\mathrm{Ca}^{2+}$ signaling lies on the other end of the scale, with decreased intracellular $\mathrm{Ca}^{2+}$ disrupting normal cellular functioning. This fits the SCA23 pathology more closely, as increased intracellular $\mathrm{Ca}^{2+}$ would lead to PC loss more quickly than previously observed (47). We demonstrate a developmental role for PDYN in the cerebellum and show that developmental abnormalities in neuronal wiring and disturbance in the PC simple/complex spike balance underlie SCA23. In addition, we propose that diazepam should be explored as a potential therapy, as it could sensitize remaining $\mathrm{GABA}_{\mathrm{A}}$ receptors and thereby alleviate SCA23 symptoms.

\section{ACKNOWLEDGEMENTS}

We would like to thank Kate Mc Intyre for editing this manuscript.

\section{CONFLICT OF INTEREST}

The authors declare that they have no conflict of interest.

\section{FUNDING INFORMATION}

This work was supported by a Rosalind Franklin Fellowship from the University of Groningen, the Jan Kornelis de Cock-Stichting, the U4 PhD program of the Behavioral and Cognitive Neuroscience graduate school of the University of Groningen and the Max Planck Society. Part of this work was performed at the University Medical Centre Groningen Microscopy and Imaging Centre, which is sponsored by the Netherlands Organization for Scientific Research (NWO grants 40-00506-98-9021 and 175-010-2009-023). None of the funding bodies were involved in the collection, analysis and interpretation of data, nor in the writing of the manuscript.

\section{DATA AVAILABILITY STATEMENT}

The data from this study will be made available upon request.

\section{REFERENCES}

1. Altier C, Zamponi GW (2006) Opioid, cheating on its receptors, exacerbates pain. Nat Neurosci 9:1465-1467.

2. Bakalkin G, Watanabe H, Jezierska J, Depoorter C, Verschuuren-Bemelmans C, Bazov I et al (2010) Prodynorphin mutations cause the neurodegenerative disorder spinocerebellar ataxia type 23. Am J Hum Genet 87:593-603.

3. Barclay J, Balaguero N, Mione M, Ackerman SL, Letts VA, Brodbeck J et al (2001) Ducky mouse phenotype of epilepsy and ataxia is associated with mutations in the Cacna2d 2 gene and decreased calcium channel current in cerebellar purkinje cells. J Neurosci 21:6095-6104.

4. Bhat S, Dao DT, Terrillion CE, Arad M, Smith RJ, Soldatov NM, Gould TD. (2012) CACNA1C (Cav1.2) in the pathophysiology of psychiatric disease. Prog Neurobiol 99:1-14.

5. Brown AM, Arancillo M, Lin T, Catt DR, Zhou J, Lackey EP et al (2019) Molecular layer interneurons shape the spike activity of cerebellar Purkinje cells. Sci Rep 9:1742.

6. Buraei Z, Yang J (2010) The subunit of voltage-gated Ca2+ channels. Physiol Rev 90:1461-1506.

7. Burgess DL, Jones JM, Meisler MH, Noebels JL (1997) Mutation of the Ca2+ channel $\beta$ subunit gene Cchb4 is associated with ataxia and seizures in the lethargic (lh) mouse. Cell. 88:385-392.

8. Catterall WA (2000) Structure and regulation of voltagegated Ca2+ channels. Annu Rev Cell Dev Biol 16:521-55.

9. Chavkin C (2013) Dynorphin-still an extraordinarily potent opioid peptide. Mol Pharmacol 83:729-736. 
10. Chen J, Sun Y, Liu X, Li J (2019) Identification of a novel mutation in the CACNA1C gene in a Chinese family with autosomal dominant cerebellar ataxia. BMC Neurol 19:157.

11. Du X, Wang J, Zhu H, Rinaldo L, Lamar K-M, Palmenberg AC et al (2013) Second cistron in CACNA1A gene encodes a transcription factor mediating cerebellar development and SCA6. Cell 154:118-133.

12. Duvick L, Barnes J, Ebner B, Agrawal S, Andresen M, Lim $\mathbf{J}$ et al (2010) SCA1-like disease in mice expressing wild-type ataxin-1 with a serine to aspartic acid replacement at residue 776. Neuron 67:929-935.

13. Ebner BA, Ingram MA, Barnes JA, Duvick LA, Frisch JL, Clark HB et al (2013) Purkinje cell ataxin-1 modulates climbing fiber synaptic input in developing and adult mouse cerebellum. J Neurosci 33(13):5806-5820.

14. Eccles JC, Ito M, Szentágothai J (1967) The Cerebellum as a Neuronal Machine. Springer: Berlin, Heidelberg.

15. Edamakanti CR, Do J, Didonna A, Martina M, Opal P (2018) Mutant ataxin1 disrupts cerebellar development in spinocerebellar ataxia type 1. J Clin Invest 128:2252-2265.

16. Fletcher CF, Lutz CM, O'Sullivan TN, Shaughnessy JD, Hawkes R, Frankel WN et al (1996) Absence epilepsy in tottering mutant mice is associated with calcium channel defects. Cell 87:607-617.

17. Furrer SA, Waldherr SM, Mohanachandran MS, Baughn TD, Nguyen K-T, Sopher Bl et al (2013) Reduction of mutant ataxin-7 expression restores motor function and prevents cerebellar synaptic reorganization in a conditional mouse model of SCA7. Hum Mol Genet 22:890-903.

18. Hansel C, Linden DJ, D'Angelo E (2001) Beyond parallel fiber LTD: the diversity of synaptic and non-synaptic plasticity in the cerebellum. Nat Neurosci 4:467-475.

19. Hauser KF, Aldrich JV, Anderson KJ, Bakalkin G, Christie MJ, Hall ED et al (2005) Pathobiology of dynorphins in trauma and disease. Front Biosci J Virtual Libr 10:216-35.

20. He H, Mahnke AH, Doyle S, Fan N, Wang C-C, Hall BJ et al (2012) Neurodevelopmental role for VGLUT2 in pyramidal neuron plasticity, dendritic refinement, and in spatial learning. J Neurosci 32:15886-15901.

21. Heiney SA, Kim J, Augustine GJ, Medina JF (2014) Precise control of movement kinematics by optogenetic inhibition of Purkinje cell activity. $J$ Neurosci 34:2321-2330.

22. Herman BH, Leslie F, Goldstein A (1980) Behavioral effects and in vivo degradation of intraventricularly administered dynorphin-(1-13) and D-Ala2-dynorphin-(1-11) in rats. Life Sci 27:883-892.

23. Hirano T (2013) Long-term depression and other synaptic plasticity in the cerebellum. Proc Jpn Acad Ser B 89:183-195.

24. Ito M (1982) Cerebellar control of the vestibulo-ocular reflex-around the flocculus hypothesis. Annu Rev Neurosci 5:275-296.

25. Ito M (2006) Cerebellar circuitry as a neuronal machine. Prog Neurobiol 78:272-303.

26. Kano M, Watanabe T, Uesaka N, Watanabe M (2018) Multiple phases of climbing fiber synapse elimination in the developing cerebellum. Cerebellum 17:722-734.

27. Lee KH, Mathews PJ, Reeves AMB, Choe KY, Jami SA, Serrano RE et al (2015) Circuit mechanisms underlying motor memory formation in the cerebellum. Neuron 86:529-540.
28. Leitch B, Shevtsova O, Guévremont D, Williams J (2009) Loss of calcium channels in the cerebellum of the ataxic and epileptic stargazer mutant mouse. Brain Res 1279:156-167.

29. Letts VA, Felix R, Biddlecome GH, Arikkath J, Mahaffey CL, Valenzuela A et al (1998) The mouse stargazer gene encodes a neuronal $\mathrm{Ca} 2+$-channel gamma subunit. Nat Genet 19:340-347.

30. Linden DJ (2003) Neuroscience. From molecules to memory in the cerebellum. Science 301:1682-1685.

31. Low C-M, Wee KS-L (2010) New insights into the not-so-new NR3 subunits of N-methyl-D-aspartate receptor: localization, structure, and function. Mol Pharmacol 78:1-11.

32. Ménard C, Tse YC, Cavanagh C, Chabot J-G, Herzog H, Schwarzer C et al (2013) Knockdown of prodynorphin gene prevents cognitive decline, reduces anxiety, and rescues loss of group 1 metabotropic glutamate receptor function in aging. J Neurosci 33:12792-12804.

33. Miyazaki T, Hashimoto K, Shin H-S, Kano M, Watanabe M (2004) P/Q-type Ca2+ channel alpha1A regulates synaptic competition on developing cerebellar Purkinje cells. $J$ Neurosci 24:1734-1743.

34. Miyazaki T, Yamasaki M, Takeuchi T, Sakimura K, Mishina M, Watanabe M (2010) Ablation of glutamate receptor GluR $\delta 2$ in adult Purkinje cells causes multiple innervation of climbing fibers by inducing aberrant invasion to parallel fiber innervation territory. $J$ Neurosci 30:15196-15209.

35. Moosmang S, Haider N, Klugbauer N, Adelsberger H, Langwieser N, Müller J, et al (2005) Role of hippocampal Cav1.2 Ca2+ channels in NMDA receptor-independent synaptic plasticity and spatial memory. $J$ Neurosci. 25:9883-9892.

36. Moosmang S, Lenhardt P, Haider N, Hofmann F, Wegener JW (2005) Mouse models to study L-type calcium channel function. Pharmacol Ther 106:347-355.

37. Nakayama H, Abe M, Morimoto C, Iida T, Okabe S, Sakimura K, Hashimoto K. (2018) Microglia permit climbing fiber elimination by promoting GABAergic inhibition in the developing cerebellum. Nat Commun 9:2830.

38. Nakayama H, Miyazaki T, Kitamura K, Hashimoto K, Yanagawa Y, Obata K et al (2012) GABAergic inhibition regulates developmental synapse elimination in the cerebellum. Neuron 74:384-396.

39. Oda S-I, Lee KJ, Arii T, Imoto K, Hyun B-H, Park IS, et al (2010) Differential regulation of Purkinje cell dendritic spines in rolling mouse Nagoya $(\mathrm{tg} / \mathrm{tg}), \mathrm{P} / \mathrm{Q}$ type calcium channel $(\alpha 1(\mathrm{~A}) / \mathrm{Ca}(\mathrm{v}) 2.1)$ mutant. Anat Cell Biol 43:211-217.

40. Perkins EM, Clarkson YL, Sabatier N, Longhurst DM, Millward CP, Jack J et al (2010) Loss of beta-III spectrin leads to Purkinje cell dysfunction recapitulating the behavior and neuropathology of spinocerebellar ataxia type 5 in humans. J Neurosci 30:4857-4867.

41. Ramirez JE, Stell BM (2016) Calcium imaging reveals coordinated simple spike pauses in populations of cerebellar Purkinje cells. Cell Rep 17:3125-3132.

42. Sakimura K, Kutsuwada T, Ito I, Manabe T, Takayama C, Kushiya E et al (1995) Reduced hippocampal LTP and spatial learning in mice lacking NMDA receptor epsilon 1 subunit. Nature 373:151-155. 
43. Schwarzer C (2009) 30 years of dynorphins-new insights on their functions in neuropsychiatric diseases. Pharmacol Ther 123:353-370.

44. Sherwood TW, Askwith CC (2009) Dynorphin opioid peptides enhance acid-sensing ion channel 1a activity and acidosis-induced neuronal death. $J$ Neurosci 29:14371-14380.

45. Shuvaev AN, Horiuchi H, Seki T, Goenawan H, Irie T, Iizuka A et al (2011) Mutant PKCy in spinocerebellar ataxia type 14 disrupts synapse elimination and long-term depression in Purkinje cells in vivo. $J$ Neurosci 31:14324-14334.

46. Singh IN, Goody RJ, Goebel SM, Martin KM, Knapp PE, Marinova Z et al (2003) Dynorphin A (1-17) induces apoptosis in striatal neurons in vitro through $\alpha$-amino-3hydroxy-5-methylisoxazole-4-propionate/kainate receptormediated cytochrome $\mathrm{C}$ release and caspase- 3 activation. Neuroscience 122:1013-1023.

47. Smeets CJLM, Jezierska J, Watanabe H, Duarri A, Fokkens MR, Meijer M et al (2015) Elevated mutant dynorphin A causes Purkinje cell loss and motor dysfunction in spinocerebellar ataxia type 23. Brain 138:2537-2552.

48. Smeets CJLM, Verbeek DS (2016) Climbing fibers in spinocerebellar ataxia: A mechanism for the loss of motor control. Neurobiol. Dis 88:96-106.

49. Smeets CJLM, Zmorzyńska J, Melo MN, Stargardt A Dooley C, Bakalkin G et al (2016) Altered secondary structure of Dynorphin A associates with loss of opioid signalling and NMDA-mediated excitotoxicity in SCA23. Hum Mol Genet 6:ddw130.

50. Striessnig J, Koschak A, Sinnegger-Brauns MJ, Hetzenauer A, Nguyen NK, Busquet P et al (2006) Role of voltagegated L-type $\mathrm{Ca} 2+$ channel isoforms for brain function. Biochem Soc Trans 34:903-909.

51. Tan-No K, Cebers G, Yakovleva T, Hoon Goh B, Gileva I, Reznikov K et al (2001) Cytotoxic effects of dynorphins through nonopioid intracellular mechanisms. Exp Cell Res 269: 54-63.

52. Verbeek DS, van de Warrenburg BP, Wesseling P, Pearson PL, Kremer HP, Sinke RJ (2004) Mapping of the SCA23 locus involved in autosomal dominant cerebellar ataxia to chromosome region 20p13-12.3. Brain. J Neurol 127:2551-2557.

53. Walker JM, Moises HC, Coy DH, Baldrighi G, Akil H (1982) Nonopiate effects of dynorphin and des-Tyrdynorphin. Science 218:1136-1138.

54. Wang SS, Denk W, Häusser M (2000) Coincidence detection in single dendritic spines mediated by calcium release. Nat Neurosci 3:1266-1273.

55. Wang W, Nakadate K, Masugi-Tokita M, Shutoh F, Aziz W, Tarusawa E et al (2013) Distinct cerebellar engrams in short-term and long-term motor learning. Proc Natl Acad Sci U S A 111:E188-E193.

56. Watanabe M, Kano M (2011) Climbing fiber synapse elimination in cerebellar Purkinje cells. Eur. J. Neurosci 34:1697-1710.

57. White JA, McKinney BC, John MC, Powers PA, Kamp TJ, Murphy GG (2008) Conditional forebrain deletion of the L-type calcium channel Ca V 1.2 disrupts remote spatial memories in mice. Learn Mem Cold Spring Harb $N$ 15:1-5.

58. Yamazaki M, Le Pichon CE, Jackson AC, Cerpas M, Sakimura K, et al (2015) Relative contribution of TARPs $\gamma-2$ and $\gamma-7$ to cerebellar excitatory synaptic transmission and motor behavior. Proc Natl Acad Sci 112:E371-79.

59. Yip J, Soghomonian J-J, Blatt GJ (2007) Decreased GAD67 mRNA levels in cerebellar Purkinje cells in autism: pathophysiological implications. Acta Neuropathol 113:559-568.

60. Zhuchenko O, Bailey J, Bonnen P, Ashizawa T, Stockton DW, Amos C et al (1997) Autosomal dominant cerebellar ataxia (SCA6) associated with small polyglutamine expansions in the alpha $1 \mathrm{~A}$-voltage-dependent calcium channel. Nat Genet 15:62-69.

\section{SUPPORTING INFORMATION}

Additional supporting information may be found in the online version of this article at the publisher's web site:

Table S1. qPCR primers.

Supplementary Material 